\title{
FDA allows second experimental drug to be tested in Ebola patients
}

\author{
Michael McCarthy
}

Seattle

The US Food and Drug Administration will allow testing of a second experimental drug, TKM-Ebola, in patients infected with the Ebola virus, the maker of the drug said on 7 August.

The drug had been put on clinical hold earlier this summer after cytokine releases detected in participants during a phase I drug dosing trial raised concerns about the drug's safety. However, in response to the Ebola outbreak in west Africa, which has claimed nearly 1000 lives, the FDA has "modified" its clinical hold to allow the drug's manufacturer, Tekmira Pharmaceuticals of Vancouver, British Columbia, to propose studies in patients infected with the virus.

In a statement the company's chief executive officer and president, Mark Murray, said that the company was willing to assist with any "responsible use" of TKM-Ebola. "We recognize the heightened urgency of this situation and are carefully evaluating options for use of our investigational drug within accepted clinical and regulatory protocols," he said.
TKM-Ebola is a cocktail of small interfering RNA which, when introduced into a cell, leads to the cleavage of messenger RNAs essential for producing three key viral proteins.

In a small proof-of-concept study, the drug was injected into two groups of macaques 30 minutes after a high challenge dose with the Zaire Ebola virus. ${ }^{1}$ One group was then treated again on days 1, 3, and 5 after the exposure, and the other group was treated every day for six consecutive days. The first regimen conferred $66 \%$ protection, and the second gave $100 \%$ protection.

1 Geisbert TW, Lee AC, Robbins M, Geisbert JB, Honko AN, Sood V, et al. Post-exposure protection of non-human primates against a lethal Ebola virus challenge with RNA interference: a proof-of-concept study. Lancet 2010;375:1896-905.

Cite this as: BMJ 2014;349:95103

๑ BMJ Publishing Group Ltd 2014 